\title{
RADICAL TEACHPR
}

A SOCIALIST, FEMINIST, AND ANTI-RACIST JOURNAL ON THE THEORY AND PRACTICE OF TEACHING

Teaching Note Nepantla: Making a Space for Discomfort in an Elementary School Classroom

by Abby Emerson

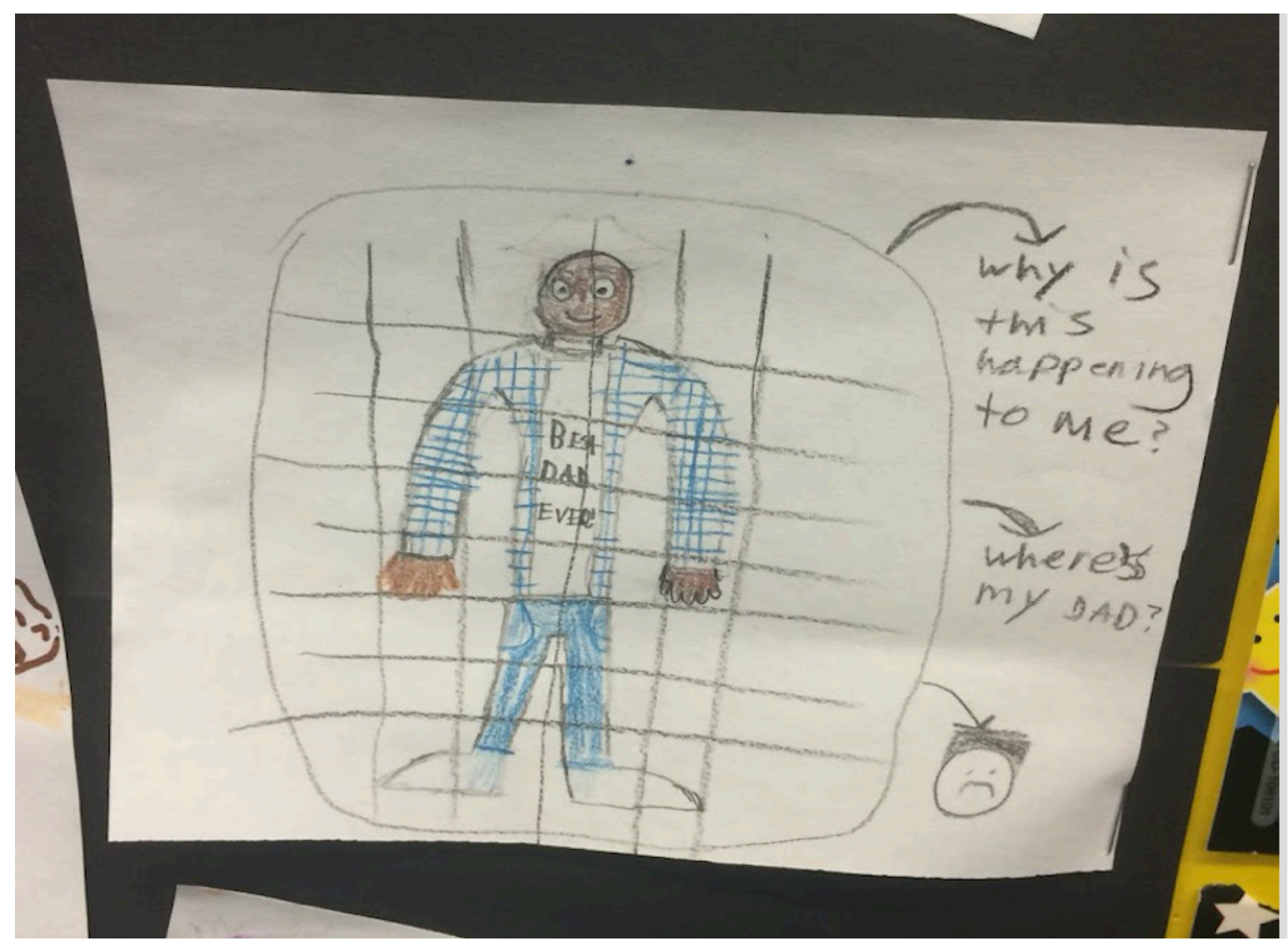


ast year, I was introduced to the work of Gloria Anzaldúa through a course I took on Black, Latina, and Transnational Feminisms as part of my professional development. Many have used and still use the Chicana scholar's work in their research, their practice, and their pedagogy, and I wanted to see what she could bring to young peoples' lives if her work was shared with them explicitly. Our classroom sits on the fourth floor of a public school on East $3^{\text {rd }}$ Street in New York City. Our classroom of 27 students is an ICT (integrated co-teaching) setting where students come with many different strengths and many different academic and social needs. There has been one concept I directly and concretely integrated into our fifth-grade classroom: nepantla.

Anzaldúa's examination of nepantla has been critical to the way in which I approach the socio-emotional work of the elementary classroom. She writes about nepantla in Interviews/Entrevistas:

With the nepantla paradigm I try to theorize unarticulated dimensions of the experience of mestizos living in between overlapping and layered spaces of different cultures and social and geographic locations, of events and realities - psychological, political, spiritual, historical, creative, imagined...

While nepantla is obviously a nuanced concept, I've explained it to my fifth-grade students in a language they can understand. My students are a loving group of children from various backgrounds. Many have family in Puerto Rico or the Dominican Republic, some come from families who immigrated from the Ukraine, and some Bengali students struggle with very real tensions around Islamaphobia in our country. Nepantla has resonated with many of them and been very powerful in processing the "layered spaces" of their lives.

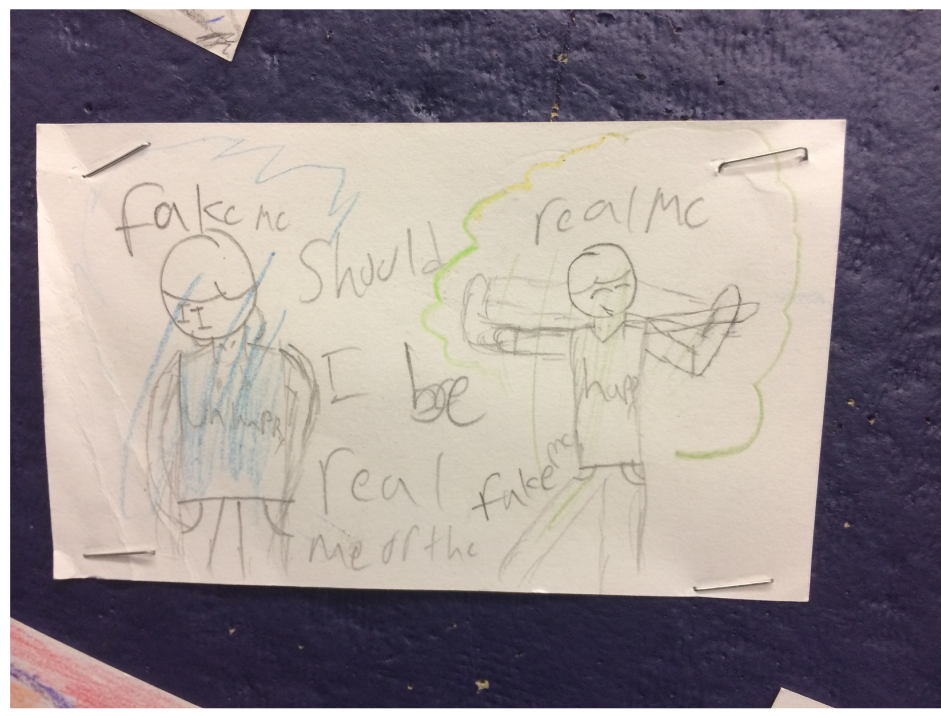

Anzaldúa writes about the transformative change that can happen when tensions around nepantla are present. Nepantla is a space of discomfort, but it possesses potential for growth, so I've worked to thoughtfully bring up those topics I sense tensions around with my students. By hearing about Anzaldúa's nepantla paradigm, my students make space for ambiguity in their lives through refreshing interpretations of the world. Children can sometimes see the world in distinct binaries (adults too!) and conversations around nepantla have helped them broaden their perspectives. It has also helped them see that they are not alone in their feelings of being "in the middle."

I first introduced nepantla during a morning meeting where we address the socio-emotional needs of the students. After having a conversation about the concept, the students brought up powerful feelings of discomfort present in their lives. One student expressed torn feelings around his father being in prison. In an artistic rendering, he first drew his father wearing a "Best Dad Ever" t-shirt and then drew the bars of prison over him. Making space for students' discomforts to be brought to the forefront allowed students' complete selves to start to have a place in the classroom. Students did not have to put on a front, but could show a range of emotions to their peers.

In later lessons students connected nepantla to conversations we'd had around gender spectrums and binaries. As we discussed multiple ways of being in regards to gender, students wondered, "Is this like nepantla?" They concluded yes. They also drew connections to historical figures struggling with activism. Historical figures like Bayard Rustin or Clara Lemlich felt compelled to public leadership for social justice, but also felt outside pressures or obligations that complicated their convictions. Students saw this as nepantla manifested. 
By focusing on Anzaldúa, my students also benefited from the presentation of highly intellectual work by women of color. Our school uses a somewhat traditional socioemotional curriculum, but I've worked to reframe the concepts they attempt to teach by bringing them up through other means. Instead of me, a White woman, explaining a concept from a binder I was handed in September, why not bring the voices and words of people that look like my students to the forefront?

Since incorporating Anzaldúa's idea of nepantla into the classroom, I have seen my students draw clear connections between abstract concepts that would otherwise seem unrelated to young minds. My recommendation for all teachers would be to find the voices of scholars, leaders, and activists that ignite your pedagogy or inspire your students and bring them directly into the classroom. It could be a scholar like Gloria Anzaldúa or it could be Civil Rights Activist Bayard Rustin. Socio-emotional content that we are already required to teach can be revised, transformed, and elevated by centering these voices.

Just as nepantla has encouraged my class to articulate the layered and complex spaces in their lives, our work as critical pedagogues must also seek to do that. As Audre Lorde wrote in "The Master's Tools Will Never Dismantle the Master's House," we must "descend into the chaos of knowledge and return with true visions of the future..." Nepantla encourages us to look beyond the black and white, the binary, the straightforward, and see different ways of existence. These existences are multi-faceted and multi-dimensional and that can be chaotic. However, when we embrace that uncertainty, we can emerge with a deeper knowledge of ourselves, our students, and our own pedagogy.

\section{Works Cited}

Anzaldúa, G. (2000) Interviews/Entrevistas. New York, NY: Routledge.

Lorde, A. (1984) The master's tools will never dismantle the master's house. In A. Lorde (Ed.), Sister Outsider: Essays and Speeches (110-114). Berkeley, CA: Crossing Press.

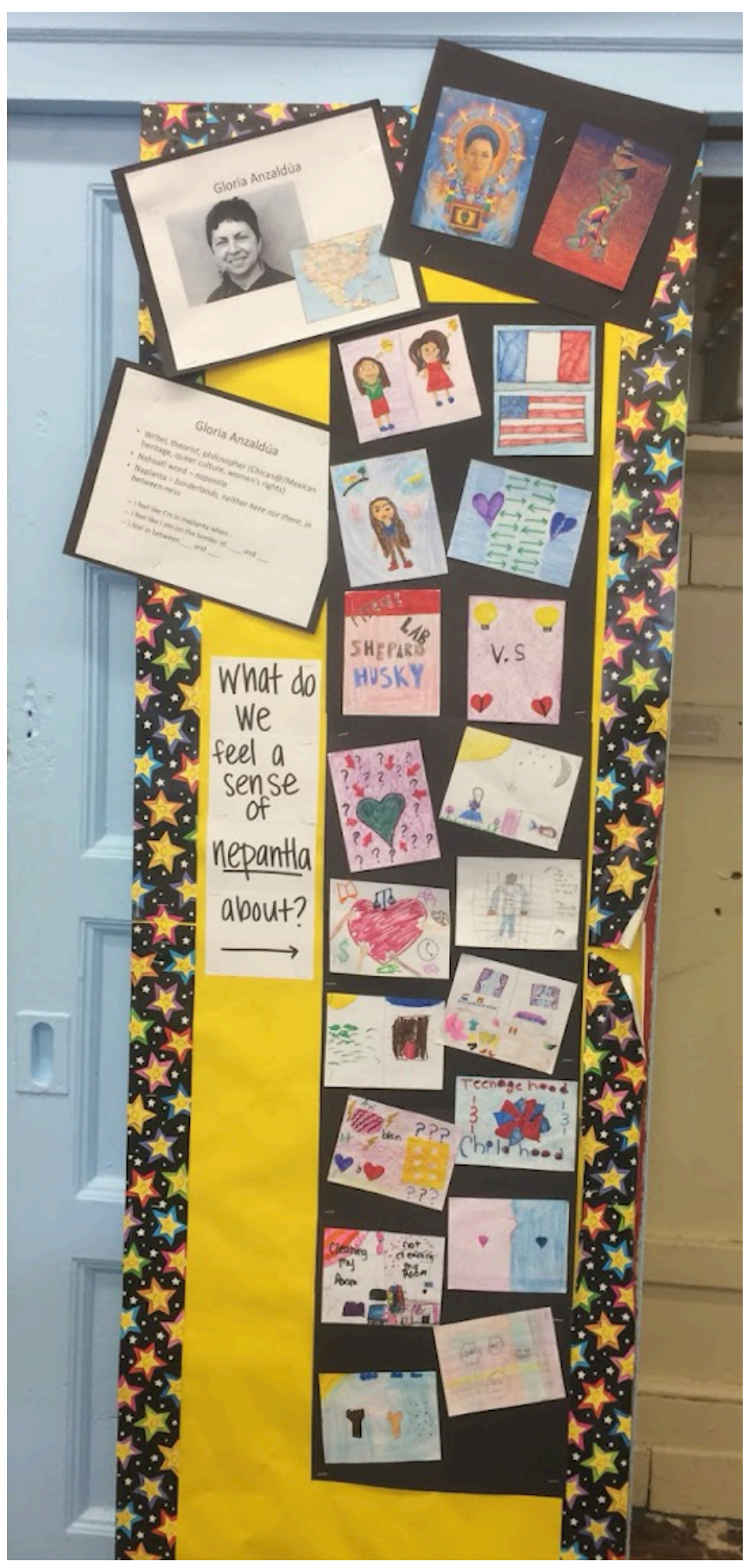

\section{(oc) EY-NC-ND}

UILIS D-Sente

This work is licensed under a Creative Commons Attribution-Noncommercial-No Derivative Works 3.0 United States License

This journal is published by the University Library System of the University of Pittsburgh as part of its D-Scribe Digital Publishing Program, and is cosponsored by the University of Pittsburgh Press.
} 